Levine, M.. Yoder, R. M., Kleinberg. J.. \& Rosenberg. J. The presolution paradox in discrimination learning. Journal of Experimental Psychology, 1968, 77, 602-608.

Suppes, P.. \& Ginsberg, R. A fundamental property of all-or-none models, binomial distributions of responses prior to conditioning, with application to concept formation in children. Psychological Review, 1963, 70, 139-161.
Trabasso, T \& Bower. G. Presolution dimensional shifts in concept identification: A test of the sampling with replacement axiom in all-or-none models. Journal of Mathematical Psychology, 1966, 3, 163-173.

(Received for publication May 29, 1973.)

\title{
Reinforcement in children: Received and expected*
}

\author{
JEAN L. BRESNAHAN $\dagger$, JOMARY P. HILLARD \\ and MARTIN M. SHAPIRO \\ Emory Lniversity'. Atlanta. Ga. 30322
}

Trial-to-trial effects of reinforcement and nonreinforcement were studied in 48 children during a simple motor task. In the absence of information regarding the availability of reinforcement during each trial, Ss responded more rapidly after a reinforced trial than after a nonreinforced trial. In the presence of a signal providing information regarding the availability of reinforcement during each trial, Ss responded more

*This research was supported in part by Contract B89-4613 from the Office of Economic Opportunity to M. M. Shapiro. J. L. Bresnahan, and I. J. Knopf. The research was submitted by J. $P$. Hilliard, under the direction of J. L. Bresnahan, in partial fulfillment of the requirements for the BA degree from Emory University.

tRequests for reprints should be sent to J. L. Bresnahan, Department of Psychology, Herbert H. Lehman College, City University of New York, Bronx, N.Y. 10468.

+P Present address: Department of Psychology, University of California at Los Angeles, Los Angeles, Calif. 90024. rapidly before an expected reinforcement than before an expected nonreinforcement.

This experiment was designed to compare the trial-to-trial effects of reinforcement and nonreinforcement upon rate of responding. The presentation of a reinforcement on Trial $n$ can affect behavior in one of two ways. It may reinforce the previous response, the response that occurred on Trial $n$, or it may provide information regarding the probability of reinforcement on Trial $n+1$. Information regarding reinforcement on Trial $\mathrm{n}+1$ may be provided inadvertently through the E's use of counterbalanced or restricted sequences. The investigation of the trial-to-trial effects of reinforcement. therefore, requires (1) the use of several probabilities of reinforcement and (2) the manipulation of information concerning reinforcement on Trial $n+1$ independent of the presentation of reinforcement on Trial $n$. 
The efficacy of a reinforcement at the end of Trial $n$ can be determined by comparing the rate of responding on Trial $n$ with the rate of responding on Trial $n+1$. One would expect the rate of responding to increase. However. the expectation of a reinforcement on Trial $n+1$ may have similar effects. Therefore, two conditions were used in this study. Ss who received discriminative stimuli which indicated the availability of reinforcement for Trial $n+1$ were expected to show the effects of the expectation of reinforcement. Ss who did not receive discriminative stimuli were expected to show only the effects of reinforcement received on Trial $n$. The potential generality of the results was enhanced by the manipulation of the probability of reinforcement which varied the relative frequency with which the discriminative and reinforcing events occurred. Reinforcement and nonreinforcement were equally likely, or one of these events was relatively infrequent. The discriminative stimuli provided maximum information when reinforcement and nonreinforcement were equally likely.

Ss were selected from high and low socioeconomic levels (SEL) because of the interaction of this $S$ characteristic with the effects of reinforcement in previous studies (Bresnahan \& Blum, 1971: Silverman \& Shapiro. 1970).

\section{METHOD}

\section{Subjects}

The Ss were 48 third graders enrolled in public schools within the metropolitan Atlanta area. One-half of the 24 high SEL Ss were white girls and one-half were white boys. One-fourth of the 24 low SEL Ss were white girls. one-fourth black girls, one-fourth white boy's. and one-fourth black boys. The mean age of the high SEL Ss was 8.91 years and the mean age of the low SEL Ss was 8.95 vears. The Ss were sampled unsystematically from the class rolls by $E$. with the restrictions that repeaters not be chosen and that each experimental group be balanced with regard to sex: the low SEL groups were additionally balanced for race.

\section{Apparatus}

The apparatus consisted of a plywood cabinet. $40.64 \times 60.96$ $x 3.81 \mathrm{~cm}$. With an upright rear panel. When placed on a desk top at a comfortable height for the seated $S$. the apparatus formed a flat work area with the panel screening the activities of $E$ from S's view. On the right-hand side of the work area was a $26.67 \times 29.21 \mathrm{~cm}$ hole in the plywood, under which was mounted a square Plexiglas pegboard with 400 drill holes (a 20 by 20 matrix). There were 10 individual Masonite pegboards which had been constructed to fit the hole in the cabinet over the pegboard matrix. Each individual board had 20 holes, arranged randomly. with one corresponding to each row and column of the matrix. When the individual test board was in place, brightly colored banana plugs or "pegs" could be inserted through the holes in both boards to make electrical contact with $400.238-\mathrm{cm}$ brass rods mounted beneath the rows of the matrix. These rods were wired so that insertion of the first peg. anrwhere in any row. activated a timer located behind the panel facing $E$. With the insertion of the 20th peg. the timer was stopped automatically. giving an accurate measure of the time taken to fill the board.

Above the pegboard area on the panel was a $30.48 \times 6.35 \mathrm{~cm}$ slot with a peg chute and tray. Pegs were fed into this tray

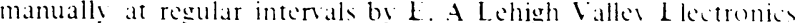
coin dispenser was mounted on the right-hand side of the panel. Centered in a vertical array above the dispenser tray were two red lamps: the lower one was $0.635 \mathrm{~cm}$ in diam and the upper one was $1.588 \mathrm{~cm}$ in diam. The lamps served as signal lights. and like the coin dispenser were controlled by switches located behind the pancl. The area of the cabinet directly beneath the coin slot was left clear for the child to place his rewards. out of his way but in plain view.

\section{Procedure}

There were six groups of four Ss within each SEL: Lach S worked steadily for 20 trials: each of these 20 trials consisted of $S$ inserting 20 pegs in a pegboard. One-third of Ss received a nickel on $80^{\prime} ;$ of the trials. one-third received a nickel on $50^{\prime}$; of the trials. and one-third received a nickel on $20^{\circ}$; of the trials. A block randomization procedure was used for determining the distribution of reinforced and nonreinforced trials for the 20\%; and $80^{\circ}$, reinforcement groups. The 20 trials were divided into four blocks of five trials each. Within each block of five trials. the position of the one rare event (the reinforced trial for the $20 \%$ group and the nonreinforced trial for the $80^{r}$; group) was randomized, with the restriction that it not occur on the first or last trial within each block. This restriction permitted the analysis of two changes of reinforcement within each block. nonreinforcement followed by a nickel and a nickel followed by nonreinforcement. For the $50, c$ reinforcement groups. there were 10 reinforced and 10 nonreinforced trials in random order. again with the restriction that two changes of reinforcement occur within each block. All Ss received a different order. For one-half of Ss. during each trial there was a signal that indicated the subsequent reinforcement or nonreinforcement: for one-half of Ss, there was no signal. The three reinforcement percentage's $(80,50,20)$ and the two signal conditions (signal and no-signal) resulted in six independent groups.

The Ss were tested individually. The $\mathrm{E}$ sat behind and to the side of the panel where she could pass boards through the slot and still be visible to $\mathrm{S}$. The $\mathrm{Ss}$ in the no-signal group were told that it was a pegboard game and to take the board and fit it into the hole. Each $\mathrm{S}$ was told to fill the board with pegs from the tray. He was told that when he finished he should pull the board out and pass it back through the slot, at which time something would happen, sometimes a loud noise (coin dispenser) and sometimes the same loud noise and a nickel prize (dispensed coin). He was asked to take the nickel prize and to put it down on the table. He was told that every time he was given a new board he should start again. For the signal group. an addition was made to the instructions. Each S was told that if the little signal light was on there would be only a loud noise when he finished: if the big signal light was on, there would be the same loud noise and a nickel prize would be given when he finished. Work with pilot Ss showed that it was necessary to insure that $\mathrm{Ss}$ actually looked at the signal light. Ss were instructed to start the next trial only after they saw the signal light. In practice. the Ss were not paced by the light; it was turned on simultaneously with the dispensing of the board. Between each trial. E recorded the time and reset the timer. dispensed reinforcement. changed the signal light when appropriate, and provided a new board. After Trial 20, the child was given an envelope in which to put his nickels and take them home.

\section{RESULTS}

Only trials involving a change in reinforcement were analyzed. The dependent variable was the difference in the time to complete the task on a pair of trials on which a nickel reinforcement was presented on one trial but not on the other trial. For the $20 \%$ reinforcement group, there were four trials on which a nickel was given. and for the $80 \%$ groups. there were four trials on which 
no nickel was given: for these two sets of groups the trials to be analyzed were predetermined by the sequence. For the $50 \%$ reinforcement groups. successive pairs of reinforced and nonreinforced trials used in the analyses were randomly sampled from the first. second, third, and fourth sets of five-trial blocks. The data were analyzed to determine the effect of (1) a change from a reinforcement to a nonreinforcement and (2) a change from a nonreinforcement to a reinforcement.

Socioeconomic level, sex, and race had no effect and are excluded from the presentation and discussion of the results. Percentage of reinforcement also had no effect.

The results are shown in Fig. 1. Two main conclusions may be drawn from the data. The Ss who received a signal for reinforcement took less time to complete a trial that preceded a reinforcement than to complete a trial that preceded nonreinforcement. This difference in task time grew progressively greater with training (blocks). Conversely, Ss who did not receive a signal for reinforcement took less time to complete a trial that followed a reinforcement than to complete a trial that followed a nonreinforcement. Furthermore, this difference in task time diminished progressively with training (blocks). All relevant comparisons yielded statistically significant results at the .05 level.

\section{DISCUSSION}

The common result of studies which investigate the trial-to-trial effects of successive reinforcements and nonreinforcements is that a reinforcement on a previous trial increases response strength on a subsequent trial (given the same stimulus or random extraneous stimulus conditions). Nevertheless, there are numerous results. with partial reinforcement (Robbins, 1971), which show that increased frequencies of reinforcement may have quite opposite effects. Response rates may be higher after relatively lower frequencies of reinforcements. Explanations for these effects typically involve attributing informational properties to the reinforcing stimulus. For example. consider the trivial case of a simple alternation. The $\mathrm{S}$ responds only after a nonreinforcement, not because nonreinforcement strengthens responding. but because the nonreinforcement provides the information that reinforcement will be available on the next trial. Or. for example, consider the gambler's fallacy in which the $\mathrm{S}$ behaves as though there is a fixed proportion of successes and failures. One success supposedly reduces the probability of another.

This experiment included groups of $\mathrm{Ss}$ for which the reinforcing stimulus was also the only available source of information regarding subsequent reinforcement (the no-signal group). The probability of reinforcement was manipulated in order to vary the amount of information obtainable from a previous reinforcement. The experiment also included groups of Ss for which additional information was available regarding subsequent reinforcement (the signal group).

When no additional information was available. a reinforcement produced faster responding on the next trial. The absence of any consistent effect of reinforcement percentage showed that the possible information provided by the reinforcement was not utilized. A reinforcement acted simply to increase response strength even when a reinforcement meant that another was unlikely to follow. Or, conversely, a nonreinforcement produced slower responding on the next trial. even when a nonreinforcement meant that a reinforcement was likely to follow.

When an additional informative signal was available regarding

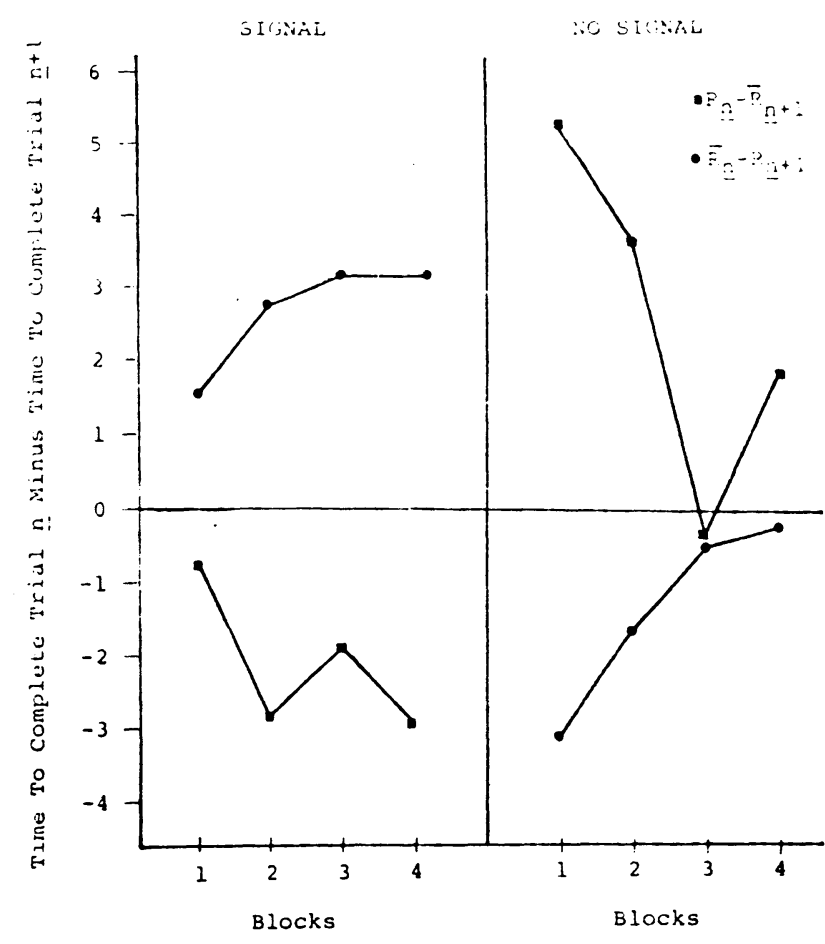

Fig. 1. Mean difference between time to complete task on Trial $n$ and time to complete task on Trial $n+1$. One trial of each pair was reinforced $(R)$ and one trial was not reinforced $(\mathbf{R})$. The signal condition is shown on the left-hand side and the no-signal condition on the right-hand side. The blocks from which the trials were sampled are shown on the abiscissa.

reinforcement on the next trial, direct control over responding passed from the reinforcing stimulus to the informative signal. Responding was faster on the trials on which reinforcement was signaled. Although a previous reinforcement undoubtedly served to maintain the subsequent informational value of the signal, responding was directly controlled by the signal rather than by the previous reinforcement. This effect of reward expectation has also been observed in the response speed of monkeys (Medin \& Davis, 1972) and in the choice behavior of adult human beings (Estes, 1972).

The obvious conclusion from these results is that behavior is controlled by the expectation of a subsequent reinforcement. In the absence of additional information, this expectation is a function of the reinforcement on the previous trial; this relationship decreases with training. In the presence of additional information, the effect of the reinforcement on the previous trial is superseded by the effect of the information: this relationship increases with training.

\section{REFERENCES}

Bresnahan, J. L., \& Blum, W. L. Chaotic reinforcement: A socioeconomic leveler. Developmental Psychology, 1971, 4. 89-92.

Estes, W. K. Reinforcement in human behavior. American Scientist, 1972, 60,723-729.

Medin, D. L., \& Davis, R. T. Memory. In A. M. Schrier and F Stollnitz (Eds.), Behavior of nonhuman primates. Vol. 5 . New York: Academic Press, 1972.

Robbins, D. Partial reinforcement: A selective review of the alleyways literature since 1960. Psychological Bulletin. 1971. 76. 415-431.

Silverman, S. M., \& Shapiro, M. M. Magnitude-probability preferences of preschool children from two socioeconomic levels. Developmental Psychology. 1970. 2. 134-139.

(Received for publication June 27. 1973.) 